\title{
Rural older people had lower mortality after accidental falls than non-rural older people
}

This article was published in the following Dove Press journal:

Clinical Interventions in Aging

6 January 2017

Number of times this article has been viewed

Jen-Wu Huang ${ }^{1,2}$

Yi-Ying Lin ${ }^{2,3}$

Nai-Yuan $\mathrm{Wu}^{4}$

Yu-Chun Chen ${ }^{5-7}$

'Department of Surgery, National Yang-Ming University Hospital, National Yang-Ming University, Yilan, Taiwan; ${ }^{2}$ Institute of Emergency and Critical Care Medicine, School of Medicine, National Yang-Ming University, Taipei, Taiwan; ${ }^{3}$ Department of Pediatrics, Heping Fuyou Branch, Taipei City Hospital, Taipei, Taiwan; ${ }^{4}$ Institute of Biomedical Informatics, National Yang-Ming University, Taipei, Taiwan; ${ }^{5}$ Department of Medical Research and Education, National Yang-Ming University Hospital, Yilan, Taiwan; ${ }^{6}$ Faculty of Medicine and School of Medicine, National Yang-Ming University, Taipei, Taiwan; ${ }^{7}$ Institute of Hospital and Health Care Administration, School of Medicine, National Yang-Ming University, Taipei, Taiwan
Correspondence: Yu-Chun Chen Department of Medical Research and Education, National Yang-Ming University Hospital, No 152, Xinmin Road, Yilan City, Yilan County 26042, Taiwan

$\mathrm{Tel}+88639325192$

Fax +88639351838

Email yuchn.chen@googlemail.com
Objective: This study aimed to investigate the mortality rate after falls of rural and non-rural older people and to explore the risk factors of mortality after falls among older people.

Patients and methods: This population-based case-control study identified two groups from a nationwide claim database (National Health Insurance Research Database in Taiwan): a rural group and a non-rural group, which included 3,897 and 5,541 older people, respectively, who were hospitalized for accidental falls (The International Classification of Diseases, Ninth Revision, Clinical Modification: E880-E888) during 2006-2009. Both groups were followed up for 4 years after falls. Four-year cumulative all-cause mortality rate after falls was calculated, and the demographic factor, comorbidity, and medications were considered as the potential risk factors of mortality after falls.

Results: The rural group had a significantly higher frequency of fall-related hospitalizations (7.4\% vs $4.3 \%, P<0.001)$, but a lower 4 -year cumulative all-cause mortality rate after falls than the non-rural group $(8.8 \%$ vs $23.4 \%, P<0.001)$. After adjusting for age, gender, comorbidity, and medication use, the rural group had a significantly lower risk of mortality after falls than the non-rural group (adjusted odds ratio $=0.32,95 \%$ confidence interval $=0.28-0.37, P<0.001$ ). Age, gender, place of residence, comorbidity, number of medications, and inappropriate medication use were independent risk factors of mortality after falls.

Conclusion: The rural older people had a higher frequency of fall-related hospitalizations but lower mortality after falls than the non-rural older people. Fall prevention programs should be adjusted for difference in place of residence.

Keywords: accidental falls, mortality, risk factors, rural population

\section{Introduction}

Accidental falls are a common public problem worldwide. More than 40,000 people die from falls globally. ${ }^{1}$ Adults aged $>65$ years have the highest risk of death or severe injury after falls. Approximately $30 \%$ of older people fall each year and the frequency exponentially increases with age. ${ }^{2-4}$ Falls not only profoundly impact a persons health but also bring huge economic burden. For older people, falls accounted for $10 \%-15 \%$ of emergency visits and up to $50 \%$ of severe injury-related hospitalizations. ${ }^{5,6}$

The occurrence of falls results from a complex interaction of multiple determinants, including older age, gender, chronic illness, poor vision, lack of exercise, impaired cognition, environmental factors, and lower socioeconomic level. ${ }^{7}$ The environmental factor, responsible for $30 \%-50 \%$ of falls for older people, might be the most crucial among these factors because it encapsulates the interaction of individual factors with the surroundings. ${ }^{8}$ Different residential environments accordingly result in distinct risk of falls for older people. A previous study has reported that older adults living in rural areas had $36 \%$ higher odds of self-reported past-year fall-related injuries than 
those living in urban areas (odds ratio $=1.36$, 95\% confidence interval $[\mathrm{CI}]=1.06-1.75) .{ }^{9}$ As rural and urban older people have numerous health-related disparities, leading to disproportionate incidence of health problems in rural older people, we are interested in whether the mortality after falls also varies between rural and non-rural areas. ${ }^{10,11}$

However, nonfatal falls result in considerable morbidity, including dependence, immobilization, and decreased function. ${ }^{12}$ It has been reported that the 1 -year mortality rate was $22 \%$ in older people with a hip fracture after a fall and was $24.5 \%$ in those with a cervical fracture after a fall. ${ }^{13}$ Therefore, to understand the potential factors predisposing the death after falls would be helpful for developing appropriate fall prevention programs.

In this study, we investigated the mortality rate after falls of rural and non-rural older people and explored the risk factors of mortality after falls among older people.

\section{Methods}

\section{Data source and study subjects}

We conducted a population-based case-control study by using the data from the National Health Insurance Research Database (NHIRD) in Taiwan. The NHIRD comprises the medical records from the single-payer National Health Insurance (NHI) program, which covers more than $99 \%$ of residents in Taiwan.

In this study, the "older people" refers to those aged $\geq 65$ years. We identified two groups of older people from the NHIRD for comparison. 1) A rural group, was identified from the Inpatient Database of Yilan County from 2006 to 2009. The database contained 52,544 older inhabitants of Yilan County. Among them, 3,897 older people were hospitalized due to accidental falls and, therefore, were grouped as the rural group. 2) A non-rural group, was extracted from a Longitudinal Cohort Database, comprising 128,359 older inhabitants from all townships in Taiwan. Among these older people, 5,541 were hospitalized for accidental falls and were grouped as the non-rural group. Both groups were followed up for 4 years after falls for the all-cause mortality.

According to the criteria adopted by the NHIRD, the rurality of Taiwan townships is defined by the following characteristics: population density, ratio of people with educational levels higher than college, ratio of people older than 65 years, ratio of people who are agriculture workers, and the number of physicians per 100,000 people. These criteria have led to the classification of Yilan County of Taiwan as a rural area. ${ }^{14}$
This study was ethically approved by the Institutional Review Board in National Yang-Ming University Hospital. Informed consent was waived because the data in the NHIRD is encrypted.

\section{Identification of falls and mortality}

The diagnoses of hospitalization were coded by The International Classification of Diseases, Ninth Revision, Clinical Modification (ICD-9-CM). The falling episode would be identified if the ICD-9-CM was between E880 and E888. If the number of falling episodes was more than two during the study period, only the first one would be taken as the index episode.

The current NHIRD did not provide the registration of death. However, due to the high and full coverage of NHI, people in Taiwan only exit insurance when they die. Thus, we adopted the date of exiting NHI as the date of death.

\section{Risk factor of mortality after falls}

Three major variables were considered as the potential risk factors of mortality after falls, including demographic factor, comorbidity, and medications. The demographic factor referred to gender, age, and the place of residence. The comorbidity was evaluated by the Charlson Comorbidity Index to reflect the severity of disease because older people tend to have multiple chronic disorders. We coded the ambulatory prescriptions 3 months prior to falls according to the Anatomical Therapeutic Chemical classification (level 4) and calculated the number of medications. The standard of inappropriate medication use was the 2012 Beers Criteria, which provides the list of drugs that should be avoided in older people. It would be considered as inappropriate medication use if an older person took any drugs that are on the list 3 months before their fall.

\section{Statistical analysis}

The continuous variables were presented as mean (standard deviation) and the categorical variables were presented as count (percentage). To compare the characteristics between the two groups, a two-sampled $t$-test and Chi-square test were used for continuous variables and categorical variables, respectively. We also calculated the 4-year cumulative allcause mortality for both groups. A logistic regression model was used in a multivariate analysis for risk factors of mortality after falls. A two-tailed $P<0.05$ indicated statistical significance. All databases were managed by Microsoft SQL server 2012 (Redmond, WA, USA), and the statistical analyses 
Table I Comparison between the rural and non-rural groups

\begin{tabular}{|c|c|c|c|c|}
\hline Variables & $\begin{array}{l}\text { Rural group } \\
(n=3,897)\end{array}$ & $\begin{array}{l}\text { Non-rural group } \\
(n=5,54 I)\end{array}$ & $\begin{array}{l}\text { Total } \\
(n=9,438)\end{array}$ & $P$-value \\
\hline Age, years ${ }^{\mathrm{a}}$ & $76.4(7.7)$ & $77.8(7.9)$ & $77.2(7.8)$ & $<0.001$ \\
\hline Female & $2,424(62.2)$ & $3,438(62.0)$ & $5,862(62.1)$ & 0.88 \\
\hline Charlson Comorbidity Index ${ }^{a}$ & $2.2(2.1)$ & $2.1(2.0)$ & $2.1(2.0)$ & $<0.001$ \\
\hline \multicolumn{5}{|l|}{ Medications } \\
\hline Number of medications ${ }^{a}$ & I3.7 (5.8) & $12.5(6.5)$ & $13.0(6.3)$ & $<0.001$ \\
\hline Use of inappropriate medication & $1,508(38.7)$ & $1,993(36.0)$ & $3,501(37.1)$ & 0.07 \\
\hline Four-year cumulative all-cause mortality & $343(8.8)$ & $1,296(23.4)$ & $1,639(17.4)$ & $<0.001$ \\
\hline Causes of fall-related hospitalization ${ }^{\mathrm{b}}$ & & & & 0.08 \\
\hline Hip fracture & $927(23.8)$ & $\mathrm{I}, 380(24.9)$ & $2,307(24.4)$ & \\
\hline Head injury & $549(14.1)$ & $105(1.9)$ & $655(6.9)$ & \\
\hline Upper extremity fracture & $507(13.0)$ & $870(15.7)$ & $1,377(14.6)$ & \\
\hline Other fractures & $456(1 \mathrm{I} .7)$ & $\mathrm{I}, 136(15.5)$ & $1,592(16.9)$ & \\
\hline Lower extremity fracture & $257(6.6)$ & $388(7.0)$ & $645(6.8)$ & \\
\hline
\end{tabular}

Notes: ${ }^{D}$ Data presented as count (percentage) or mean (standard deviation). ${ }^{\circ}$ Only causes with frequencies greater than $5 \%$ were listed.

were performed using IBM SPSS Statistics for Windows, Version 19.0 (IBM Corporation, Armonk, NY, USA).

\section{Results}

Among the 52,544 older inhabitants of a rural area in Taiwan, 3,897 people experienced at least one hospitalization due to an accidental fall during 2006-2009. The frequency in the rural area was significantly higher than that in the non-rural area $(7.4 \%$ [3,897 of 52,544$]$ vs $4.3 \%$ [5,541 of 128,359$]$, $P<0.001)$. The comparison of the rural group and the nonrural group was presented in Table 1. These two groups had several significant differences. The rural group was significantly younger ( 76.4 years vs 77.8 years, $P<0.001$ ), had a greater Charlson Comorbidity Index (2.2 vs 2.1, $P<0.001$ ), and took more medications $(13.7 \%$ vs $12.5 \%, P<0.001)$ than the non-rural group. The proportion of inappropriate medication use was also higher in the rural group $(38.7 \%$ vs $36.6 \%, P=0.07$ ), but the difference did not achieve statistical significance.

By further analyzing the hospitalization of older people in the rural area, falls accounted for $9 \%$ of hospitalization and was the fourth reason of hospitalization. Although the causes of fall-related hospitalization differed between the rural and non-rural groups, it did not achieve a statistically significant difference. The most frequent complication in the rural area was femur fracture $(23.8 \%)$, followed by head injury (14.1\%) and upper extremity fracture (13.0\%). Fractures accounted for $70 \%$ of fall-related hospitalizations. The most frequent cause of fall-related hospitalizations in a non-rural area was a hip fracture (24.9\%), followed by upper extremity fracture (15.7\%) and other fractures (15.5\%). The 4-year cumulative all-cause mortality rate after a fall in the non-rural group was $23.4 \%(95 \% \mathrm{CI}=22.1-24.7)$, which was significantly higher than that of the rural group (8.8\%) (95\% CI $=7.9-9.8)$.

Table 2 shows the results of the multivariate analysis. The independent risk factors of mortality after falls included male, older age, non-rural area, severer comorbidity, higher number of medications taken, and presence of inappropriate medication use. After adjusting for age, gender, comorbidity, number of medications, and inappropriate medication use, the rural group had a significantly lower risk of mortality after falls than the non-rural group (adjusted odds ratio $=0.32$, 95\% CI $=0.28-0.37, P<0.001)$ (Table 2 ).

\section{Discussion}

Rural and non-rural areas are distinct in terms of socioeconomic condition, surrounding environment, and the acces-

Table 2 Multivariate analysis for risk factors of mortality after falling

\begin{tabular}{|c|c|c|}
\hline Risk factors & $\begin{array}{l}\text { Adjusted odds } \\
\text { ratio }(95 \% \mathrm{Cl})\end{array}$ & $P$-value \\
\hline Age & $1.07(1.07-1.08)$ & $<0.001 * * *$ \\
\hline \multicolumn{3}{|l|}{ Gender } \\
\hline Male & $1.77(1.58-1.98)$ & $<0.001 * * *$ \\
\hline Female & - & \\
\hline \multicolumn{3}{|l|}{ Place of residence } \\
\hline Rural area & $0.32(0.28-0.37)$ & $<0.00 I^{* * *}$ \\
\hline Non-rural area & - & \\
\hline Charlson Comorbidity Index & $1.12(1.09-1.16)$ & $<0.001 * * *$ \\
\hline \multicolumn{3}{|l|}{ Medications } \\
\hline Number of medications & $0.99(0.98-1.00)$ & $0.022 *$ \\
\hline Use of inappropriate medication & $1.35(1.19-1.53)$ & $<0.00 I^{* * *}$ \\
\hline
\end{tabular}

Notes: $* P<0.05, * * *<<0.001$.

Abbreviation: $\mathrm{Cl}$, confidence interval. 
sibility to health services. ${ }^{15}$ The urban-rural difference also leads to some health-related disparities. ${ }^{10,11,16}$ It has been noted that rural older people fall more frequently than urban older people. But seldom have studies compared the mortality after falls for older people between different places of residence. Additionally, as the risk factors of falls have been analyzed thoroughly, it would be helpful to further understand the potential factors predisposing the mortality after falls. . $^{1,8,9,17-19}$

In this study, we found that the rural older people had a significantly lower mortality, even after more frequent falls. There were several possible reasons for this result. The first was the lower incidence of fractures in the rural area, which has been similarly reported in many countries. ${ }^{20-26}$ Most investigators suggested that the difference of fracture incidence could be explained by the higher bone mineral density (BMD) of a rural population. ${ }^{21-23,27-30}$ A populationbased 15-year cohort study of females aged $\geq 50$ years in Sweden reported that the rural population had significantly higher BMD, lower prevalence of osteoporosis, and lower incidence of hip fractures. ${ }^{21}$ A study in Norway, which included 7,333 females aged $\geq 65$ years, found that urban females had a higher rate of forearm fractures, and the authors commented that this was due to the lower forearm BMD of urban females than that of rural females. ${ }^{22}$ Therefore, as fracture is the major cause of fatal falls, the rural population might have less morbidity and less mortality even after more frequent falls because of their higher BMD and their lower incidence of fractures. ${ }^{31-33}$

The second was the rural-urban difference of industrial distribution. According to the government statistics in Taiwan, the percentage of the agricultural population in Yilan County at the end of 2009 was approximately 25\%, which was almost twice than that in all of Taiwan (13\%). ${ }^{34,35}$ The rural group in this study consequently comprised of farmers who usually spend the majority of their time undertaking outdoor physical activity even after falls. Previous studies have revealed that early mobilization in older people after fractures could enhance functional recovery and reduce mortality, and mobility function was the independent risk factor for recurrence falls. ${ }^{36-38}$ Therefore, the rural older people might recover earlier after falls and have less morbidity and mortality than the non-rural older people.

The last reason was the rural-urban difference between the etiologies of falls. Previous studies report that environment-related factors and weather could impact the occurrence of falls in older people. ${ }^{8,39}$ According to government statistics in Taiwan, there were more single storied houses but less buildings with elevators in Yilan County. ${ }^{15}$ Additionally, the area of a house is larger and the weather is more wet and humid in Yilan County. ${ }^{15,40}$ The different home surroundings, environments, and weather between the rural and urban areas consequently lead to different etiologies of falls. For example, rural older people might have more chance of slipping outdoors or falling from indoor stairs, but less chance of stumbling inside their home or on a street. These different etiologies of falls, which usually result in diverse types of injuries, could explain the rural-urban difference of mortality after falls.

In addition to the place of residence, this study also noted that males, comorbidity, number of medications taken, and the use of inappropriate medication were also the independent risk factors of mortality after falls. The results were concordant with the reported predictors of death after a hip fracture in older people. ${ }^{41-43}$ As hip fractures accounted for the major cause of death after falls, it is reasonable to find similar risk factors of mortality between falls and hip fractures.

\section{Limitations}

There were several limitations in this secondary data analysis. 1) The fall episode was identified by fall-related hospitalization and fall-related outpatient care was included. Therefore, selection bias might not be avoided and the incidence of falls would be underestimated. 2) Some fall-related variables were not taken into consideration, for example, the reasons of falls and the place of falls. Several individual factors, which might impact on the prognosis of falls, were also not included, such as education level, body mass index, and BMD. 3) Due to the limitation of the claim database, we did not calculate the frequency of multiple injuries. Potential reporting bias might exist in this study.

\section{Conclusion}

Rural older people had a higher frequency of fall-related hospitalizations but lower mortality after falls than non-rural older people. The place of residence is an independent risk factor of death after falls for older people. Fall prevention programs should be adjusted in consideration of the urbanrural difference.

\section{Acknowledgments}

This study is based in part on data from the NHIRD provided by the Bureau of National Health Insurance, Department of Health, and managed by the National Health Research Institutes. The interpretation and conclusion contained herein do not represent those of the National Health Insur- 
ance administration, Department of Health, or the National Health Research Institutes.

Funding for this study was from a research grant from the National Yang-Ming University Hospital (RD2012-015).

\section{Author contributions}

$\mathrm{J}-\mathrm{W}$ Huang provided the conception and obtained the grant. Y-Y Lin collected, analyzed, and interpreted the data. N-Y Wu performed statistical analysis and drafted the manuscript. Y-C Chen supervised and designed the study. All authors contributed toward data analysis, drafting and revising the paper and agree to be accountable for all aspects of the work.

\section{Disclosure}

The authors report no conflicts of interest in this work.

\section{References}

1. World Health Organization. Media Centre: Falls. Available from: http://www.who.int/mediacentre/factsheets/fs344/en/. Accessed March 1, 2016

2. Blake AJ, Morgan K, Bendall MJ, et al. Falls by elderly people at home: prevalence and associated factors. Age Ageing. 1988;17(6): 365-372.

3. Prudham D, Evans JG. Factors associated with falls in the elderly: a community study. Age Ageing. 1981;10(3):141-146.

4. Campbell AJ, Reinken J, Allan BC, Martinez GS. Falls in old age: a study of frequency and related clinical factors. Age Ageing. 1981; 10(4):264-270.

5. Scuffham $P$, Chaplin S, Legood R. Incidence and costs of unintentional falls in older people in the United Kingdom. $J$ Epidemiol Community Health. 2003;57(9):740-744.

6. Hill AD, Pinto R, Nathens AB, Fowler RA. Age-related trends in severe injury hospitalization in Canada. $J$ Trauma Acute Care Surg. 2014; 77(4):608-613.

7. Tideiksaar R. Geriatric falls: assessing the cause, preventing recurrence. Geriatrics. 1989;44(7):57-61, 64.

8. Rubenstein LZ. Falls in older people: epidemiology, risk factors and strategies for prevention. Age Ageing. 2006;35(Suppl 2):ii37-ii41.

9. Stewart Williams J, Kowal P, Hestekin H, et al. Prevalence, risk factors and disability associated with fall-related injury in older adults in low- and middle-income countries: results from the WHO Study on global AGEing and adult health (SAGE). BMC Med. 2015; 13:147.

10. Goeres LM, Gille A, Furuno JP, et al. Rural-urban differences in chronic disease and drug utilization in older Oregonians. J Rural Health. 2016;32(3):269-279.

11. Eberhardt MS, Pamuk ER. The importance of place of residence: examining health in rural and nonrural areas. Am J Public Health. 2004; 94(10):1682-1686.

12. Sterling DA, O'Connor JA, Bonadies J. Geriatric falls: injury severity is high and disproportionate to mechanism. J Trauma. 2001;50(1) 116-119.

13. Cooper Z, Mitchell SL, Lipsitz S, et al. Mortality and readmission after cervical fracture from a fall in older adults: comparison with hip fracture using National Medicare data. J Am Geriatr Soc. 2015;63(10): 2036-2042.

14. Liu CY, Hung YT, Chuang YL, et al. Incorporating development stratification of Taiwan townships into sampling design of large scale health interview survey. $J$ Health Manag. 2006;4(1):1-22.
15. National Statistics. Directorate General of Budget, Accounting and Statistics, Executive Yuan, Taiwan. Available from: http://eng.stat.gov. tw. Accessed November 1, 2016.

16. Williams F, Jeanetta S, O'Brien DJ, Fresen JL. Rural-urban difference in female breast cancer diagnosis in Missouri. Rural Remote Health. 2015;15(3):3063.

17. Ganz DA, Bao Y, Shekelle PG, Rubenstein LZ. Will my patient fall? JAMA. 2007;297(1):77-86.

18. Lord SR, Menz HB, Sherrington C. Home environment risk factors for falls in older people and the efficacy of home modifications. Age Ageing. 2006;35(Suppl 2):ii55-ii59.

19. Yoo JS, Kim CG, Yim J, Jeon MY. Factors influencing falls in the frail elderly individuals in urban and rural areas. Aging Clin Exp Res. 2016;28(4):687-697.

20. Sanders K, Nicholson G, Ugoni A, Seeman E, Pasco J, Kotowicz M. Fracture rates lower in rural than urban communities: the Geelong Osteoporosis Study. J Epidemiol Community Health. 2002;56(6): 466-470.

21. Rosengren BE, Ahlborg HG, Gärdsell P, et al. Bone mineral density and incidence of hip fracture in Swedish urban and rural women 1987-2002. Acta Orthop. 2010;81(4):453-459.

22. Omsland TK, Ahmed LA, Grønskag A, et al. More forearm fractures among urban than rural women: the NOREPOS study based on the Tromsø study and the HUNT study. J Bone Miner Res. 2011;26(4): $850-856$.

23. Pongchaiyakul C, Nguyen TV, Kosulwat V, Rojroongwasinkul N, Charoenkiatkul S, Rajatanavin R. Effect of urbanization on bone mineral density: a Thai epidemiological study. BMC Musculoskelet Disord. 2005;6:5.

24. Mannius S, Mellström D, Odén A, Rundgren A, Zetterberg C. Incidence of hip fracture in western Sweden 1974-1982. Comparison of rural and urban populations. Acta Orthop Scand. 1987;58(1):38-42.

25. Sernbo I, Johnell O, Andersson T. Differences in the incidence of hip fracture. Comparison of an urban and a rural population in southern Sweden. Acta Orthop Scand. 1988;59(4):382-385.

26. Chevalley T, Herrmann FR, Delmi M, et al. Evaluation of the ageadjusted incidence of hip fractures between urban and rural areas: the difference is not related to the prevalence of institutions for the elderly. Osteoporos Int. 2002;13(2):113-118.

27. Gu W, Rennie KL, Lin X, Wang Y, Yu Z. Differences in bone mineral status between urban and rural Chinese men and women. Bone. 2007; 41(3):393-399.

28. Gärdsell P, Johnell O, Nilsson BE, Sernbo I. Bone mass in an urban and a rural population: a comparative, population-based study in southern Sweden. J Bone Miner Res. 1991;6(1):67-75.

29. Sundberg M, Düppe H, Gärdsell P, Sernbo I. Bone mineral density in adolescents. Higher values in a rural area-a population-based study of 246 subjects in southern Sweden. Acta Orthop Scand. 1997; 68(5):456-460.

30. Meyer HE, Berntsen GK, Søgaard AJ, et al. Higher bone mineral density in rural compared with urban dwellers: the NOREPOS study. Am J Epidemiol. 2004;160(11):1039-1046.

31. Ellis AA, Trent RB. Hospitalized fall injuries and race in California. Inj Prev. 2001;7(4):316-320.

32. Buczak-Stec E, Goryński P. Fall related hospital admissions among seniors in Poland in 2010. Przegl Epidemiol. 2013;67(1):57-62, 141-144.

33. Stevens JA, Corso PS, Finkelstein EA, Miller TR. The costs of fatal and non-fatal falls among older adults. Inj Prev. 2006;12(5): 290-295.

34. Budget, Accounting, and Statistics Department, Yilan County, Taiwan. 2009 Annual Report. Available from: http://bgacst.e-land.gov.tw/News. aspx? $=$ C6DA56487665B34F\&sms=DB8F640FF065C9A1. Accessed March 1, 2016.

35. Council of Agriculture, Executive Yuan, Taiwan. Yearly Report of Taiwan's Agriculture. Available from: http://agrstat.coa.gov.tw/sdweb/ public/maintenance/Announce.aspx. Accessed March 1, 2016. 
36. Weerink LB, Folbert EC, Kraai M, Smit RS, Hegeman JH, van der Velde D. Thoracolumbar spine fractures in the geriatric fracture center: early ambulation leads to good results on short term and is a successful and safe alternative compared to immobilization in elderly patients with two-column vertebral fractures. Geriatr Orthop Surg Rehabil. 2014;5(2):43-49.

37. Nevitt MC, Cummings SR, Kidd S, Black D. Risk factors for recurrent nonsyncopal falls. A prospective study. JAMA. 1989;261(18): 2663-2668.

38. Chu LW, Chi I, Chiu AY. Incidence and predictors of falls in the Chinese elderly. Ann Acad Med Singapore. 2005;34(1):60-72.

39. Stevens JA, Thomas KE, Sogolow ED. Seasonal patterns of fatal and nonfatal falls among older adults in the U.S. Accid Anal Prev. 2007; 39(6):1239-1244.
40. Central Weather Bureau, Executive Yuan, Taiwan. Climate Statistics. Available from: http://www.cwb.gov.tw/V7e/climate/dailyPrecipitation/ dP.htm. Accessed November 1, 2016.

41. Roche JJ, Wenn RT, Sahota O, Moran CG. Effect of comorbidities and postoperative complications on mortality after hip fracture in elderly people: prospective observational cohort study. BMJ. 2005;331(7529): 1374.

42. Kannegaard PN, van der Mark S, Eiken P, Abrahamsen B. Excess mortality in men compared with women following a hip fracture. National analysis of comedications, comorbidity and survival. Age Ageing. 2010; 39(2):203-209.

43. Gosch M, Wörtz M, Nicholas JA, et al. Inappropriate prescribing as a predictor for long-term mortality after hip fracture. Gerontology. 2014; 60(2):114-122.
Clinical Interventions in Aging

\section{Publish your work in this journal}

Clinical Interventions in Aging is an international, peer-reviewed journal focusing on evidence-based reports on the value or lack thereof of treatments intended to prevent or delay the onset of maladaptive correlates of aging in human beings. This journal is indexed on PubMed Central, MedLine,

\section{Dovepress}

CAS, Scopus and the Elsevier Bibliographic databases. The manuscript management system is completely online and includes a very quick and fair peer-review system, which is all easy to use. Visit http://www.dovepress. com/testimonials.php to read real quotes from published authors. 